\title{
NMDA receptor-dependent processes in the medial prefrontal cortex are important for acquisition and the early stage of consolidation during trace, but not delay eyeblink conditioning
}

\author{
Kaori Takehara-Nishiuchi, Shigenori Kawahara, ${ }^{1}$ and Yutaka Kirino \\ Laboratory of Neurobiophysics, School of Pharmaceutical Sciences, The University of Tokyo, Bunkyo-ku, Tokyo 113-0033, Japan
}

\begin{abstract}
Permanent lesions in the medial prefrontal cortex (mPFC) affect acquisition of conditioned responses (CRs) during trace eyeblink conditioning and retention of remotely acquired CRs. To clarify further roles of the mPFC in this type of learning, we investigated the participation of the $\mathrm{mPFC}$ in mnemonic processes both during and after daily conditioning using local microinfusion of the $\mathrm{GABA}_{\mathrm{A}}$ receptor agonist muscimol or the NMDA receptor antagonist APV into the rat mPFC. Muscimol infusions into the mPFC before daily conditioning significantly retarded $\mathrm{CR}$ acquisition and reduced CR expression if applied after sufficient learning. APV infusion also impaired acquisition of CRs, but not expression of well-learned CRs. When infusions were made immediately after daily conditioning, acquisition of the CR was partially impaired in both the muscimol and APV infusion groups. In contrast, rats that received muscimol infusions $3 \mathrm{~h}$ after daily conditioning exhibited improvement in their CR performance comparable to that of the control group. Both the pre- and post-conditioning infusion of muscimol had no effect on acquisition in the delay paradigm. These results suggest that the mPFC participates in both acquisition of a CR and the early stage of consolidation of memory in trace, but not delay eyeblink conditioning by NMDA receptor-mediated operations.
\end{abstract}

The prefrontal cortex is implicated in many cognitive functions, including working memory, the temporal organization of behavior, and emotion (Kolb 1984; Goldman-Rakic 1990; Fuster 1997), and also is presumed to have the most dynamic and richest interaction with other brain regions (Fuster 2001). Recent reports have expanded the importance of the rabbit and rodent medial prefrontal cortex (mPFC) to hippocampus-dependent motor learning, e.g., trace classical eyeblink conditioning. Since the essential neuronal circuitry for eyeblink conditioning is relatively well characterized, investigating the role of the mPFC in this task may contribute to our understanding of the nature of the mPFC's interaction with other brain areas.

Trace eyeblink conditioning is a hippocampus-dependent variation of classical eyeblink conditioning, a process that depends critically on the cerebellum and brainstem (for review, see Thompson et al. 1997). In this paradigm, the conditioned stimulus (CS) and the unconditioned stimulus (US) are separated by a stimulus-free trace interval. Previous studies using permanent lesion methods have revealed that pre-conditioning lesioning of the hippocampus (Solomon et al. 1986; Moyer et al. 1990; McGlinchey-Berroth et al. 1997; Beylin et al. 2001), the medial prefrontal cortex (mPFC) (Kronforst-Collins and Disterhoft 1998; Weible et al. 2000, 2003; McLaughlin et al. 2002), the entorhinal cortex (Ryou et al. 2001), and the mediodorsal thalamus (Powell and Churchwell 2002) all impair acquisition of the trace eyeblink-conditioned response (CR), suggesting that the circuitry for this learning covers multiple regions of the brain, as others have previously proposed (Weiss and Disterhoft 1996; Green and Woodruff-Pak 2000). Furthermore, this circuitry is reorganized

\section{'Corresponding author.}

E-mail kawahara@mol.f.u-tokyo.ac.jp; fax 81-3-5841-4805.

Article and publication are at http://www.learnmem.org/cgi/doi/10.1101/ Im.5905. after the CR has been completely acquired. Retention of a recently acquired CR is mediated mainly by the hippocampus (Kim et al. 1995; Takehara et al. 2002, 2003a) and the cerebellum (Woodruff-Pak et al. 1985; Takehara et al. 2003a), but only marginally by the mPFC (Powell et al. 2001; Takehara et al. 2003a). Retention of a remotely acquired CR is mediated by the MPFC and the cerebellum (Takehara et al. 2003a).

Although these previous studies using permanent lesion methods have indicated an involvement of the mPFC in trace eyeblink conditioning, this method has only limited utility when we seek a detailed understanding of the participation of the mPFC, because permanent lesions affect not only acquisition, but also consolidation and retrieval. Therefore, further studies that can specify the stage of memory and also elucidate the underlying molecular process are required for a more detailed understanding of the mPFC's precise role. Here we investigated the involvement of the $\mathrm{mPFC}$ in mnemonic processes during and after daily conditioning using microinfusion of the $\gamma$-aminobutyric acid type $A\left(G_{A B A}\right)$ receptor agonist muscimol. In addition, we examined the involvement of $N$-Methyl-D-aspartate (NMDA) receptors in this process using microinfusion of the NMDA receptor antagonist 2-amino-5-phosphonovaleric acid (APV), because synaptic plasticity in the prelimbic area of the mPFC depends on NMDA receptors (Hirsch and Crepel 1991; Jay et al. 1995). A preliminary report of some of these data has been presented previously in abstract form (Takehara et al. 2003b).

\section{Results}

Effect of pre-conditioning infusion into the mPFC of muscimol or APV on trace CR acquisition

Figure 1 shows the effect on acquisition of microinfusion into the $\mathrm{mPFC}$ of the $\mathrm{GABA}_{\mathrm{A}}$ receptor agonist muscimol or the NMDA 
receptor antagonist APV before daily trace eyeblink conditioning with trace intervals of $500 \mathrm{msec}$. Rats received a microinfusion of one of the drugs before daily conditioning (PBS: $n=11$, Muscimol: $n=9$, APV: $n=8$ ) The adaptive CR\% of the rats receiving PBS infusion before daily pseudoconditioning is also shown (Pseudo: $n=6$ ). Phase 1 (sp 1 and sp 2) was designed to examine the effect of the drug on spontaneous eyeblink frequency by putting the rats in the conditioning box without the presentation of the CS and US. In sp 2, rats received a microinfusion of muscimol, APV, or PBS. Statistical analysis using a one-way ANOVA on sp 2 revealed a significant group effect $\left(F_{(2,25)}=5.93\right.$, $P<0.01$ ). Post hoc analysis (Tukey HSD) revealed that the muscimol-infusion group differed significantly from the PBS-infusion group $(P<0.01)$, although the APV-infusion group did not, suggesting that inactivation of the $\mathrm{mPFC}$ reduces spontaneous eyeblinking. Phase 2 (sessions 1-10) was designed to examine the drugs' effects on CR acquisition. As shown in Figure 1, the muscimol-, the APV-infusion, and the pseudoconditioning groups exhibited a lower adaptive CR\% than the control group. This was confirmed by a two-way repeated measures ANOVA; there was a significant interaction between groups and sessions $\left(F_{(27,306)}=5.48, P<0.001\right)$ and significant effects of group $\left(F_{(3,34)}=19.8, P<0.001\right)$ and of session $\left(F_{(9,306)}=15.6\right.$, $P<0.001)$. Furthermore, post hoc analysis (Tukey HSD) revealed that both the muscimol- and the APV-infusion groups differed significantly from the PBS-infusion group (both $P<0.01$ ), but not from the pseudoconditioning group $(P>0.05)$. The simple main effects of session were significant in the muscimol-infusion group $\left(F_{(9,250)}=3.64, P<0.05\right)$, but not in the APV-infusion group $\left(F_{(9,250)}=0.958, P>0.05\right)$. Post hoc analysis (Tukey HSD) confirmed a significant difference between the adaptive CR\% in session 1 and that in session 10 in the muscimol-infusion group $(P<0.05)$, but not in the APV-infusion group $(P>0.05)$. The infusion effects were fully reversible, since all groups increased

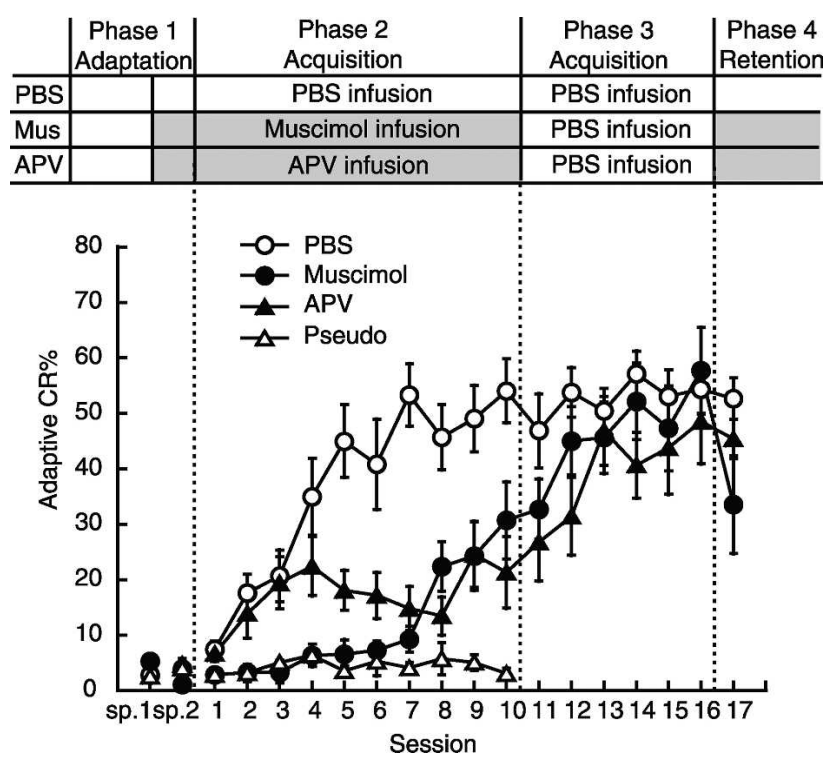

Figure 1. Effect on trace $C R$ acquisition of intra-mPFC infusion of muscimol or APV before daily conditioning. Average adaptive CR\% in the PBS-infusion group (PBS: $n=11$ ), muscimol-infusion group (Muscimol: $n=9$ ), APV-infusion group (APV: $n=8$ ), and the PBS-infusion group with pseudoconditioning (Pseudo: $n=6)$. ( $(S p)$ Spontaneous eyeblink frequency. Both the muscimol- and APV-infusion groups exhibited severe impairment in CR acquisition. When switched to PBS-infusion in Phase 3, both groups acquired the CR at approximately the level of the control group. Reinfusion of muscimol slightly affected CR expression in Phase 4, but reinfusion of APV had no effect in Phase 4. Error bar, SEM. their adaptive CR\% and the adaptive CR\% of the muscimol- and APV-infusion groups reached an asymptotic level in a manner comparable to the control group in Phase 3 (sessions 11-16), during which both groups received PBS infusions. A two-way repeated measures ANOVA on sessions 11-16 revealed that there was no significant interaction between groups and sessions $\left(F_{(10,125)}=0.991, P>0.05\right)$, and no significant effects of group $\left(F_{(2,25)}=2.09, P>0.05\right)$, but there was a significant effect of session $\left(F_{(5,125)}=5.58, P<0.001\right)$. A two-way repeated measures ANOVA on sessions 14-16 revealed that there was no significant interaction between groups and sessions $\left(F_{(4,50)}=0.808\right.$, $P>0.05)$, and no significant effects of group $\left(F_{(2,25)}=0.970\right.$, $P>0.05)$ or of session $\left(F_{(2,50)}=1.51, P>0.05\right)$. Finally, in Phase 4 (session 17) we tested the effect of muscimol or APV on the expression of well-learned CRs. In contrast to the successful expression of the CR observed in the APV-infusion group, the muscimol-infusion group tended to show fewer adaptive CRs. Although this difference did not reach statistical significance (oneway ANOVA: $\left.F_{(2,25)}=2.93, P>0.05\right)$, the adaptive CR\% in session 17 was noticeably reduced compared with that in session 16 ( $t$ test, $P<0.05)$. Similar results were obtained when we analyzed all of the CRs observed in an entire CS-US interval (data not shown).

To investigate the drug's effect on the temporal pattern of the CR between groups, we analyzed the CR onset latency and peak latency of these animals (all CRs observed in the entire CS-US interval were included). The CR onset latency of the PBS-, muscimol-, and APV-infusion groups was $436.7 \pm 30.9 \mathrm{msec}$, $430.4 \pm 44.9 \mathrm{msec}$, and $359.3 \pm 38.5 \mathrm{msec}$, respectively. The CR peak latency of the PBS-, muscimol-, and APV-infusion groups was $578.8 \pm 18.6 \mathrm{msec}, 555.4 \pm 26.0 \mathrm{msec}$, and $546.6 \pm 16.9$ msec, respectively. There were no differences in the CR onset latencies or the peak latencies among the groups (one-way ANOVA, both $P>0.05$ ). These results showed that (1) the muscimol infusions into the $\mathrm{mPFC}$ before daily conditioning significantly retarded CR acquisition, slightly affected expression of the pre-acquired CRs, and also affected spontaneous eyeblink frequency, and (2) the APV infusion into the mPFC before daily conditioning significantly impaired acquisition of the trace CR, but it had no effect on expression of the pre-acquired CRs or on spontaneous eyeblink frequency. These impairments were not attributable to the abnormal timing of the acquired CRs because neither drug had a significant effect on either the CR onset or peak latency.

\section{Effect of post-conditioning infusion into the mPFC of muscimol or APV on trace CR acquisition}

In the next experiment, we investigated the drug effects on consolidation processes, which are presumed to occur after daily conditioning. Figure 2 shows the effect on CR acquisition of posttraining infusion of muscimol or APV into the mPFC immediately after daily conditioning during trace eyeblink conditioning (PBS: $n=12$, Muscimol: $n=7$, APV: $n=9$ ). The adaptive CR $\%$ of the rats receiving PBS infusion immediately after daily pseudoconditioning is also shown (Pseudo: $n=6$ ). The treatment schedule is shown above the graph. Following the adaptation session in Phase 1 (sp 1-sp 2), in Phase 2 (sessions 1-10) the rats were trained in a trace paradigm with microinfusion of PBS, muscimol, or APV immediately after the daily conditioning. Animals with muscimol or APV infused into the MPFC exhibited a lower adaptive CR\% than that of the control group. Statistical analysis using a two-way repeated measures ANOVA revealed that there was a significant interaction between groups and sessions $\left(F_{(27,270)}=2.60, P<0.001\right)$ and significant effects of both group $\left(F_{(3,30)}=27.0, P<0.001\right)$ and session $\left(F_{(9,270)}=13.1, P<0.001\right)$. Post hoc analysis (Tukey HSD) confirmed that the muscimol- and 


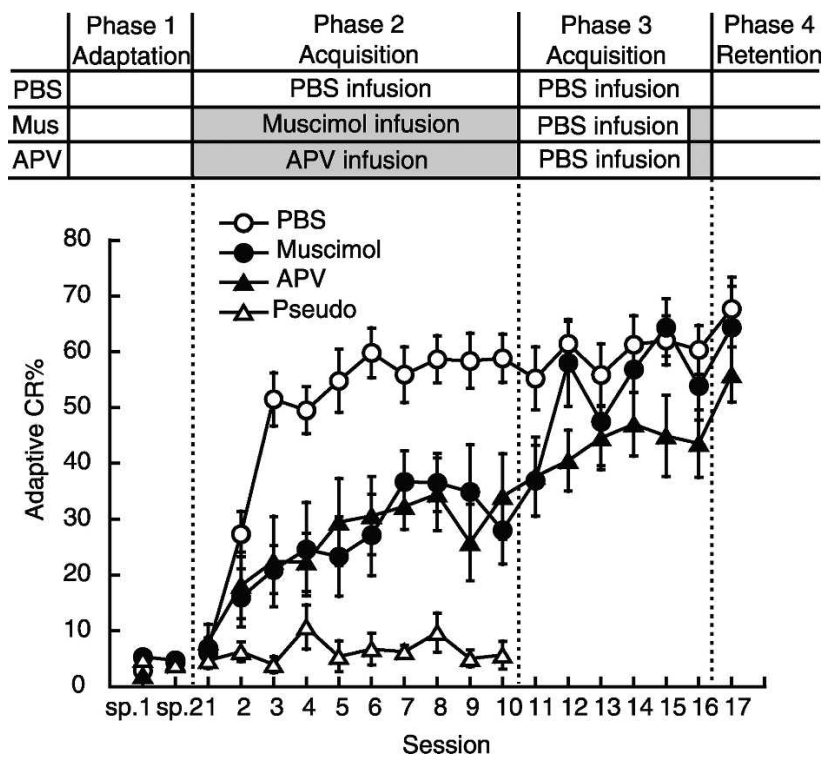

Figure 2. Effect on trace $C R$ acquisition of intra-mPFC infusion of muscimol or APV immediately after daily conditioning. The rats received microinfusions immediately after their daily conditioning. Average adaptive CR\% in the PBS-infusion group (PBS: $n=12$ ), the muscimol-infusion group (Muscimol: $n=7$ ), the APV-infusion group (APV: $n=9$ ), and the PBS-infusion group with pseudoconditioning (Pseudo: $n=6$ ). (Sp) Spontaneous eyeblink frequency. Both the muscimol- and APV-infusion groups exhibited severe impairment in acquisition of the CR. Error bar, SEM.

APV-infusion groups were significantly different from the PBSinfusion group (both $P<0.001$ ) and the pseudoconditioning group (both $P<0.01$ ). The simple main effects of session were significant in both the muscimol-infusion group $\left(F_{(9,250)}=5.11\right.$, $P<0.05)$, and in the APV-infusion group $\left(F_{(9,250)}=3.64\right.$, $P<0.05$ ). Post hoc analysis (Tukey HSD) confirmed that there was a significant difference between the adaptive CR\% in session 1 and that in session 10 in the muscimol- and APV-infusion groups (both $P<0.05$ ). To examine the residual effect of repeated treatments with these drugs, all rats received PBS infusions in Phase 3 (sessions 11-16). As expected, all groups increased their adaptive CR\% and the muscimol- and APV-infusion groups reached an asymptotic level of learning in a manner comparable to the control group during this overtraining period. A two-way repeated measures ANOVA on sessions 11-16 revealed that there was no significant interaction between groups and sessions $\left(F_{(10,125)}=0.912, P>0.05\right)$, but there were significant effects of group $\left(F_{(2,25)}=3.81, P<0.05\right)$ and session $\left(F_{(5,125)}=3.67\right.$, $P<0.01)$. A two-way repeated measures ANOVA on sessions $14-$ 16 revealed that there was no significant interaction between groups and sessions $\left(F_{(4,50)}=0.719, P>0.05\right)$, and no significant effect of group $\left(F_{(2,25)}=3.03, P>0.05\right)$ or of session $\left(F_{(2,50)}=1.43\right.$, $P>0.05)$. Finally, the rats again received the muscimol or APV infusion immediately after their conditioning in session 16 to examine the drug's effect the next day on retention of the fully acquired CR. Both the muscimol- and APV-infusion groups retained their CRs in session 17 as successfully as the PBS-infusion group did (one-way ANOVA, $P>0.05$ ). Similar results were also obtained when we analyzed all of the CRs observed in an entire CS-US interval (data not shown).

We also analyzed the latencies to the onset and to the peak of the CRs in these animals to quantify the drug effects on the timing of CRs (all CRs observed in an entire CS-US interval were included). The CR onset latency of the PBS-, muscimol-, and APV-infusion groups was $387.8 \pm 29.6 \mathrm{msec}, 421.9 \pm 43.9 \mathrm{msec}$, and $418.2 \pm 33.5 \mathrm{msec}$, respectively. The CR peak latency of the
PBS-, muscimol-, and APV-infusion groups was $601.5 \pm 18.9$ msec, $567.9 \pm 29.0 \mathrm{msec}$, and $571.4 \pm 26.9 \mathrm{msec}$, respectively. There was no difference in either the onset latency or the peak latency between groups (one-way ANOVA, both $P>0.05$ ). These results suggest that the consolidation process that occurs immediately after daily trace eyeblink conditioning was partially disrupted by infusion of the muscimol or APV into the mPFC. In addition, these manipulations were effective only during the initial phase of CR acquisition. The impairments are not attributable to the abnormal timing of the acquired CRs, since neither drug had any significant effect on the CR onset or on peak latency.

\section{Effects on trace $C R$ acquisition of delaying infusion into the mPFC of muscimol by $3 \mathrm{~h}$}

In order to specify the time window for the involvement of the $\mathrm{mPFC}$ in the consolidation process, we investigated the effect of muscimol infusion $3 \mathrm{~h}$ after daily trace conditioning (PBS: $n=7$; Muscimol: $n=9$ ) (Fig. 3). The treatment schedule is shown above the graph. Following the adaptation session in Phase 1 (sp 1-sp 2 ), the rats received a PBS or muscimol infusion $3 \mathrm{~h}$ after their daily conditioning. The muscimol-infusion group acquired the adaptive CR in a manner that was comparable to the control group. Statistical analysis using a two-way repeated measures ANOVA revealed that there was no significant interaction between the groups and sessions $\left(F_{(9,126)}=0.472, P>0.05\right)$ and no significant effect of group $\left(F_{(1,14)}=0.002, P>0.05\right)$, but there was a significant session effect $\left(F_{(9,126)}=15.5, P<0.001\right)$. Similar results were also obtained if we analyzed all of the CRs observed in an entire CS-US interval (data not shown). In addition, quantitative analysis of the latencies to the onset and to the peak of the CRs supported a lack of difference in the temporal pattern between groups (all CRs observed in the entire CSUS interval were included). The CR onset latency of the PBSand muscimol-infusion groups was $398.0 \pm 31.7 \mathrm{msec}$ and $536.3 \pm 30.5 \mathrm{msec}$, respectively. The CR peak latency of the PBSand muscimol-infusion groups was $413.4 \pm 31.7 \mathrm{msec}$ and $592.7 \pm 19.6 \mathrm{msec}$, respectively. The CR onset latency and the peak latency of the muscimol-infusion group did not differ significantly from those of the control PBS-infusion group ( $t$-test,

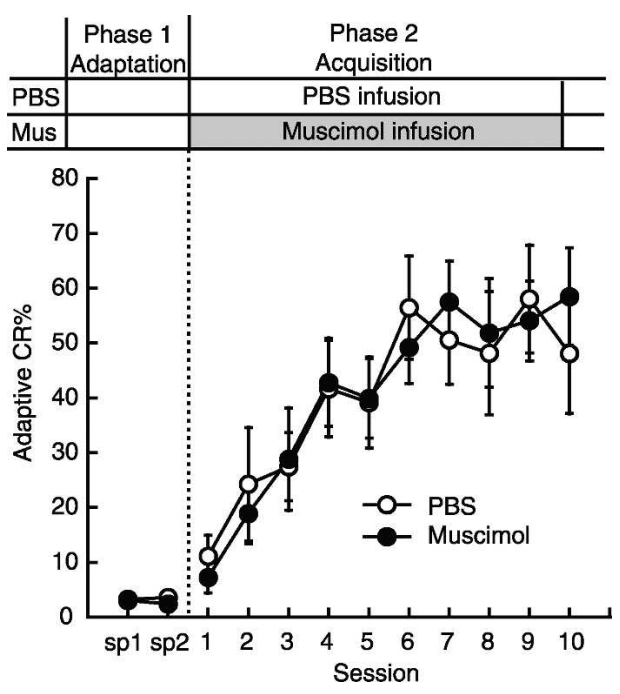

Figure 3. Effect on trace $C R$ acquisition of 3-h delayed intra-mPFC infusion of muscimol. Average adaptive CR\% in the PBS-infusion group (PBS: $n=7$ ) and the muscimol-infusion group (Muscimol: $n=9$ ). (Sp) Spontaneous eyeblink frequency. The muscimol-infusion group acquired the $\mathrm{CR}$ in a way comparable to the PBS-infusion group. Error bar, SEM. 
both $P>0.05)$. These results suggest that muscimol infusion into the $\mathrm{mPFC} 3 \mathrm{~h}$ after daily conditioning had no effect on trace CR acquisition. Since these results suggested that the consolidation processes which occur immediately after training probably end within $3 \mathrm{~h}$, we did not investigate the effect of APV infusion beyond $3 \mathrm{~h}$ after training.

\section{Effects of pre- and post-conditioning infusions into the mPFC of muscimol on delay CR acquisition}

It is worth asking whether the impairments observed in the trace 500 paradigm can be attributed to the important contribution of the mPFC to mnemonic processes during and immediately after daily conditioning in this paradigm or to the general timedependent disruptive effects of mPFC inactivation. To this end, we investigated the effect on CR acquisition of muscimol infusion before or immediately after daily conditioning in the delay paradigm with an interstimulus interval of $250 \mathrm{msec}$ (delay 250 paradigm), in which permanent lesion of the mPFC has no effect on CR acquisition (Kronforst-Collins and Disterhoft 1998; Weible et al. 2000) (Figs. 4, 5). Figure 4 shows the effect on acquisition of pre-conditioning infusion of muscimol into the mPFC during delay eyeblink conditioning (PBS: $n=6$; Muscimol: $n=7)$. In Phase 1 , the rats that had received a microinfusion of muscimol showed fewer spontaneous eyeblinks than rats that had received an infusion of PBS in sp $2(P<0.05$, paired $t$-test). In Phase 2, the muscimol-infusion group acquired the delay CR in a manner comparable to the control group. Statistical analysis using a two-way repeated measures ANOVA revealed that there was no significant interaction between the groups and sessions $\left(F_{(6,66)}=0.367, P>0.05\right)$ and no significant effect of group $\left(F_{(1,11)}=0.036, P>0.05\right)$, but there was a significant session effect $\left(F_{(6,66)}=26.6, P<0.001\right)$. Qualitative analysis of $\mathrm{CR}$ onset and peak latency was conducted. The CR onset latency of the PBSand muscimol-infusion groups was $120.4 \pm 8.1 \mathrm{msec}$ and $117.6 \pm 7.3 \mathrm{msec}$, respectively. The CR peak latency of the PBSand muscimol-infusion groups was $148.5 \pm 3.4 \mathrm{msec}$ and $139.6 \pm 2.8 \mathrm{msec}$, respectively. The CR onset latency and the peak latency of the muscimol-infusion group did not differ sig-

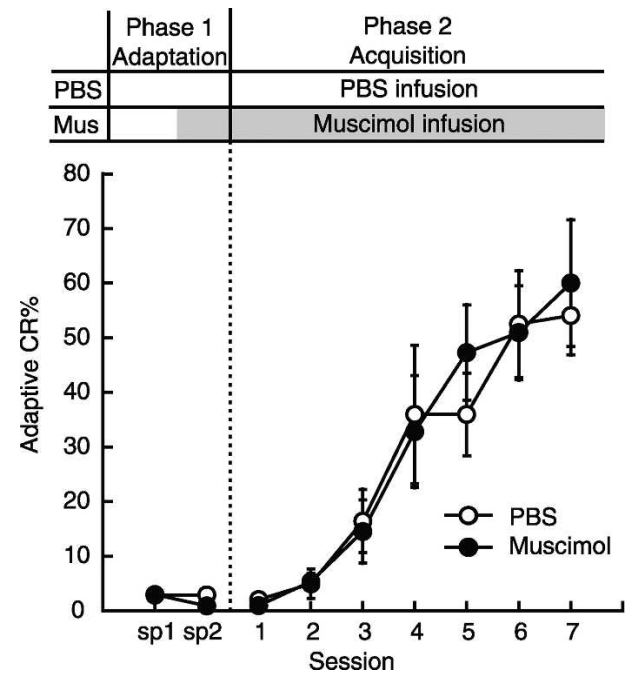

Figure 4. Effect on delay $C R$ acquisition of pre-conditioning intramPFC infusion of muscimol. Average adaptive CR\% in the PBS-infusion group (PBS: $n=6$ ) and the muscimol-infusion group (Muscimol: $n=7$ ). (Sp) Spontaneous eyeblink frequency. The muscimol-infusion group acquired the CR in a way comparable to the PBS-infusion group. Error bar, SEM.

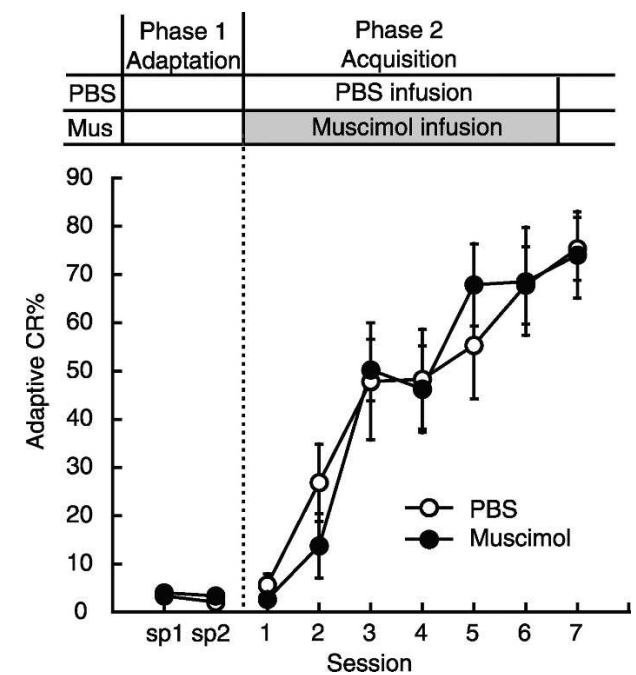

Figure 5. Effect on delay $C R$ acquisition of immediate postconditioning intra-mPFC infusion of muscimol. Average adaptive CR\% in the PBS-infusion group (PBS: $n=7$ ) and the muscimol-infusion group (Muscimol: $n=6$ ). (Sp) Spontaneous eyeblink frequency. The muscimolinfusion group acquired the CR in a way comparable to the PBS-infusion group. Error bar, SEM.

nificantly from the latencies of the control PBS-infusion group ( $t$-test, both $P>0.05$ ).

Next, we investigated the effect of the post-conditioning infusion of muscimol on CR acquisition in the delay 250 paradigm (PBS: $n=7$; Muscimol: $n=6$ ) (Fig. 5). Following the adaptation session in Phase 1 (sp 1-sp 2), the rats received PBS or muscimol infusion immediately after their daily conditioning. The muscimol-infusion group acquired the adaptive CR in a manner comparable to the control group. Statistical analysis using a two-way repeated measures ANOVA revealed that there was no significant interaction between groups and sessions $\left(F_{(6,66)}=0.746, P>0.05\right)$ and no significant effect of group $\left(F_{(1,11)}=0.003, P>0.05\right)$, but there was a significant session effect $\left(F_{(6,66)}=34.0, P<0.001\right)$. In addition, qualitative analysis of $\mathrm{CR}$ onset and peak latency was conducted. The CR onset latency of the PBS- and muscimol-infusion groups was $121.1 \pm 3.2 \mathrm{msec}$ and $128.4 \pm 8.2 \mathrm{msec}$, respectively. The CR peak latency of the PBS- and muscimol-infusion groups was $144.1 \pm 1.6 \mathrm{msec}$ and $145.9 \pm 3.5 \mathrm{msec}$, respectively. The CR onset latency and the peak latency of the muscimol-infusion group did not differ significantly from the latencies of the control PBS-infusion group ( $t$-test, both $P>0.05$ ). These results suggest that the muscimol infusion into the mPFC did not affect mnemonic processes either during or immediately after daily conditioning in the delay 250 paradigm.

\section{Histology}

Figure $6 \mathrm{~A}$ shows a representative photomicrograph of a brain section from a rat used in the present experiment. Using Nisslstained sections, we required that the cannula placements be within the appropriate area of the prelimbic cortex and that damage to the tissue be limited to just around the cannula. Of a total of 122 rats, 12 were rejected by this criterion, leaving 28 rats for the pre-conditioning groups, 28 rats for the post-conditioning groups, and 16 rats for the 3 -h groups in the trace paradigm, and in the delay paradigm, leaving 13 rats for the pre-conditioning groups and 13 rats for the post-conditioning groups. In the pseudoconditioning group, there were six rats left in the pre- and post-conditioning groups. Figure $6 \mathrm{~B}-\mathrm{F}$ depict the cannula tip 
A

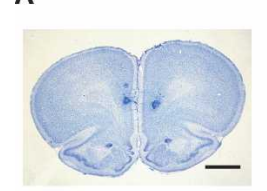

B

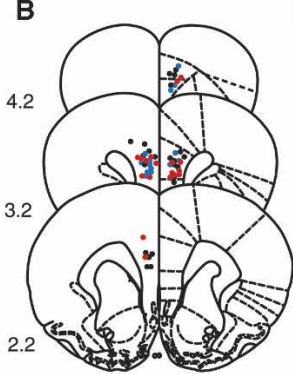

C

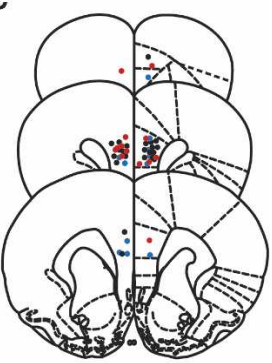

Muscino

E
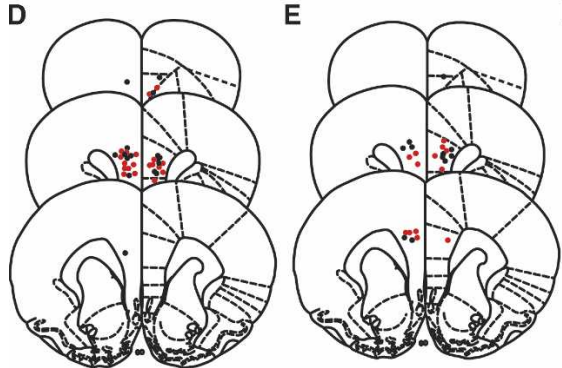

$\mathbf{F}$

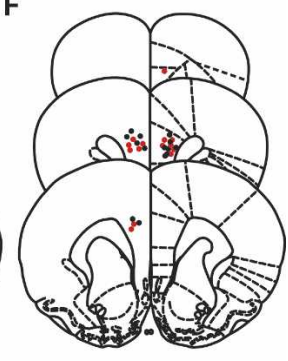

Figure 6. Histological reconstructions of cannula placements. (A) A representative photomicrograph of a coronal section. Scale bar, $2 \mathrm{~mm}$. $(B-F)$ Schematic illustration of the location of cannula tips in the mPFC in rats that received an infusion before daily trace eyeblink conditioning $(B)$, immediately after trace conditioning (C), $3 \mathrm{~h}$ after trace conditioning $(D)$, before daily delay conditioning $(E)$, or immediately after delay conditioning $(F)$. A black dot, red dot, or blue dot represents a placement in a PBS-, muscimol-, or APV-infusion group, respectively. Numbers to the left indicate stereotaxic coordinates relative to bregma. Reprinted with permission from Elsevier (c) 1986, Paxinos and Watson 1986.

placements of the rats included in the present study (Trace Paradigm $[\mathrm{B}]$ the pre-conditioning groups, $[\mathrm{C}]$ the post-conditioning groups, [D] the 3-h groups; Delay Paradigm [E] the preconditioning groups, $[\mathrm{F}]$ the post-conditioning groups). The cannula tip placements in the experimental subjects did not differ from the placements in the controls. The cannula tip placements in the pseudoconditioning group did not differ from the placements in the other groups (data not shown).

\section{Correlation of cannula position with drug efficacy}

The relationship between drug efficacy and cannula position was examined by correlating the percent impairment (relative to the adaptive CR\% in the PBS infusion group in session 10 for each group) with the estimated distance between the targeted position and the actual position of the guide cannulae using the AP and DV coordination (the muscimol-infusion group: Fig. 7A; the APV-infusion group: Fig. 7B in the pre-conditioning treatment; the muscimol-infusion group: Fig. 7C; and the APV-infusion group: Fig. 7D in the post-conditioning treatment). There was a significant correlation between the distance of the actual position of the guide cannulae from the targeted position and drug efficacy in the APV-infusion group in the pre-conditioning treatment (Pearson $r=0.943, P<0.001$; Fig. 7B), although the correlations were not significant in the other three groups (Fig. $7 \mathrm{~A}, \mathrm{C}, \mathrm{D})$. In these three groups, we confirmed the lack of correlation by correlating the percent impairment with the actual AP or DV coordination of the cannula position (data not shown). Thus, with increasing distance from the targeted site, APV infusions became less efficacious in the pre-conditioning treatment. Linear regression analysis revealed that the $\mathrm{X}$ intercept of the regression line was 2.08, indicating that the radius of the area of drug diffusion was within $2 \mathrm{~mm}$. Therefore, the drug mainly diffused into the rostral mPFC. In addition, lack of correlation in

the other three groups suggests that the partial acquisition observed in these groups cannot be attributed to insufficient drug diffusion.

\section{Discussion}

In the present study, we investigated the participation of the $\mathrm{mPFC}$ in mnemonic processes during and after daily trace eyeblink conditioning by using microinfusion of muscimol or APV in several treatment protocols. We found that reversible inactivation of the mPFC during daily conditioning significantly retarded CR acquisition and reduced CR expression if applied after sufficient learning in trace eyeblink conditioning. Blockade of NMDA receptors in the mPFC during the daily conditioning severely impaired trace CR acquisition, although it had little effect on expression of well-learned CRs. Reversible inactivation and NMDA receptor blockade also partially blocked CR acquisition when they were performed immediately after, but not as late as $3 \mathrm{~h}$ after daily trace conditioning. Acquisition during the delay 250 paradigm was not impaired by inactivation of the mPFC either during or immediately after daily conditioning. These results suggest that the mPFC plays important roles specifically in acquisition of the CR and in the early stage of consolidation of trace eyeblink CRs, and that these processes require the integrity of the NMDA receptor system in the mPFC.

Disterhoft and his collaborators (Weible et al. 2000) have reported that aspiration of the caudal mPFC centering on the caudal anterior cingulate cortex (ACC) — but not aspiration of the rostral mPFC centering on the prelimbic cortex (PrL) - severely impaired acquisition of the CR during trace, but not delay eyeblink conditioning in rabbits, confirming their own earlier finding (Kronforst-Collins and Disterhoft 1998). On the other hand, McLaughlin et al. (2002) reported that electrolytic lesioning of the rostral mPFC retarded trace CR acquisition, but lesioning of the caudal mPFC had no significant effect. Similar results have also been obtained with lesions to the mediodorsal thalamus, which is reciprocally connected to the mPFC (Powell and Churchwell 2002). Post-learning lesioning of the mPFC only slightly affected CR retention if it was performed $1 \mathrm{~d}$ after learn-
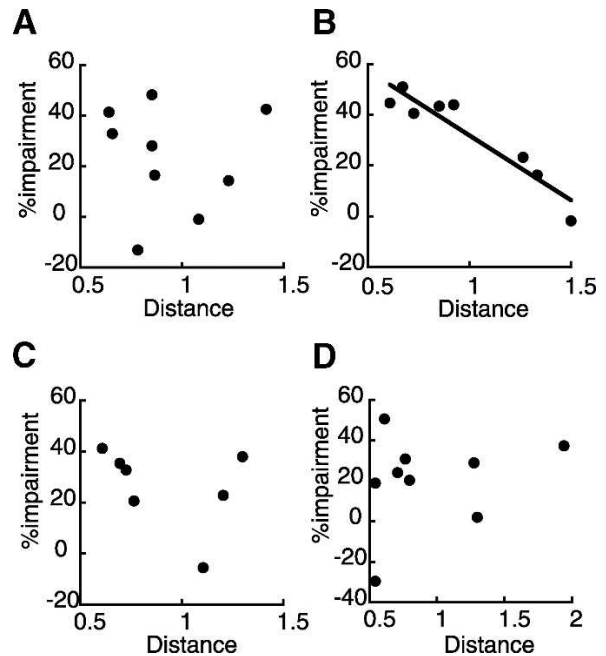

Figure 7. The correlation between the distance between targeted location and actual location of the guide cannula (millimeters) and efficacy of the drug (percent impairment relative to PBS infusion). ( $A$ ) The correlation of the muscimol-infusion group, $(B)$ the APV-infusion group in the pre-conditioning treatment, $(C)$ the muscimol-infusion group, and $(D)$ the APV-infusion group in the post-conditioning treatment. A significant correlation was observed only in the APV-infusion group in the preconditioning treatment. 
ing (Powell et al. 2001; Takehara et al. 2003a). In the present study, however, the rats that received infusions of muscimol into the rostral mPFC exhibited significant impairment in both acquisition and expression of well-learned CRs. It is unlikely that the impairments observed in the muscimol-infusion group were produced by mere performance deficits, because muscimol infusion before the daily conditioning had no effect on delay CR acquisition. Moreover, the adaptive CR\% of the muscimolinfusion group did not show any saving effects after the drug treatments ceased (see sessions 13-16 in Fig. 2). Therefore, the impairment observed in the muscimol-infusion group appears to be attributable to the disruption of mnemonic processes in the mPFC during daily conditioning. There is a possibility that permanent loss of the mPFC may induce compensation, and the role of the MPFC may be partially substituted for by the remaining mPFC and/or other brain areas, which might explain why the impairments produced by the permanent lesions were not as severe as those caused by the reversible inactivation. It is worth noting that the muscimol-infusion group exhibited some residual ability to learn (Fig. 2). This result can be interpreted in one of two ways as follows: (1) muscimol did not sufficiently diffuse to inactivate the rostral mPFC completely, or (2) some learning was possible when the rostral mPFC was completely inactivated. In order to assess drug efficacy, we looked at the correlation between cannula position and the extent of the learning impairment (Fig. 7). There was no correlation between cannula position and the extent of the impairment in the muscimolinfusion group (Fig. 7A), although there was a significant correlation in the APV-infusion group (Fig. 7B), whose cannula distributions were similar to those of the muscimol-infusion group (Fig. 6B,C). Therefore, the insufficient impairment observed in the muscimol-infusion group most likely suggests that the mPFC is involved in, but not critical for encoding the CS-US association and expression of well-learned CRs during trace eyeblink conditioning. Perhaps the role of the mPFC is modulation of the mnemonic processes in other brain areas such as the hippocampus and the cerebellum. However, we did not directly measure the area in which the drug's concentration was within the effective concentration range. Therefore, the possibility of insufficient manipulations of the mPFC cannot be totally excluded.

Although the animals are trained over several days in trace eyeblink conditioning, unlike single-trial learning, each daily conditioning session is thought to initiate a consolidation process that builds upon its predecessor. Here we have shown that, at least in the early stage of learning, activation of the mPFC is required immediately after training (but not $3 \mathrm{~h}$ later). Because the delayed inactivation of the MPFC had no effect on CR acquisition, the effect of muscimol could not be anterograde on the subsequent conditioning performed on the next day, rather, the effects are retrograde, affecting consolidation of the information acquired on the current day. This time-limited involvement of the $\mathrm{mPFC}$ during the first $3 \mathrm{~h}$ of the post-training period is similar to the time course of consolidation in delay eyeblink conditioning (Hernandez and Powell 1983; Scavio et al. 1992; Attwell et al. 2002; Cooke et al. 2004). It is worth noting that not only blockade of NMDA receptors, but also inactivation of the mPFC immediately after the training had no effect on retention of the acquired CRs the next day, suggesting that requirement of the mPFC for post-training processing is limited to that stage when the memory is beginning to be formed. These results suggest that post-training processes in the $\mathrm{mPFC}$ are necessary for memory fixation, by which short-term synaptic modifications induced by the daily conditioning are stabilized and become stable changes in connectivity between neurons (Eichenbaum 2002) during the intervals between the daily trace-conditioning sessions. As is evi- dent in Figure 2, both the muscimol- and APV-infusion groups exhibited some residual ability to learn. These results suggest two possibilities as follows: (1) the time course of the drug's efficacy was insufficient to block the whole process of consolidation, or (2) there are other brain areas that participate in the consolidation process.

In accordance with other learning tasks, animals with systemic injection of (+)MK-801 (Thompson and Disterhoft 1997; Takatsuki et al. 2001), mutant mice lacking the NMDA receptor subunit $\epsilon 1$ (Kishimoto et al. 2001), and those with reduced expression of $\epsilon 2$ subunits (Takehara et al. 2004) all exhibit severe impairments in acquisition during trace eyeblink conditioning. In the present trace eyeblink conditioning study, we have shown that APV infusions into the mPFC severely impaired acquisition and partially impaired consolidation, but did not impair expression of well-learned CRs. Our results are consistent with the earlier findings, revealing the involvement of NMDA receptors in mnemonic processes during and immediately after daily conditioning. The method also has enabled us to identify one of the sites of action, the mPFC. Therefore, it is possible that NMDAdependent synaptic modification (Hirsch and Crepel 1991; Jay et al. 1995) and/or NMDA-mediated modulation of transmission (Compte et al. 2000) in the mPFC are important for memory formation during trace eyeblink conditioning. However, it has been reported that blockade of NMDA receptors in the MPFC produces a concurrent increase in dopamine release in this area (Feenstra et al. 2002), which could cause abnormal neuronal activity in the mPFC (Yang and Seamans 1996). Therefore, elevation of dopamine levels by APV infusion also might explain the impairment observed in this group.

In trace eyeblink conditioning, the hippocampus is required for both acquisition (Solomon et al. 1986; Moyer et al. 1990; Beylin et al. 2001) and retention of a recently acquired memory, but not of a remotely acquired one (Kim et al. 1995; Takehara et al. 2002, 2003a). These results suggest that the hippocampus is important for the early processes of memory (acquisition and consolidation), but the later processes (storage and retrieval) are mediated by other brain areas. We have proposed that the mPFC is one of the critical components for these later processes because permanent lesions in the mPFC preclude retention of a remotely acquired memory (Takehara et al. 2003a). Pre-conditioning lesions in the mPFC affect CR acquisition (Kronforst-Collins and Disterhoft 1998; Weible et al. 2000; McLaughlin et al. 2002) and post-conditioning lesions slightly affect retention of recently acquired CRs (Powell et al. 2001; Takehara et al. 2003a). We have confirmed the involvement of the mPFC in acquisition, the early stage of consolidation and expression by using reversible inactivation and NMDA receptor blockade in the present study. Therefore, the $\mathrm{mPFC}$ is involved in acquisition, consolidation, storage, and retrieval, but its importance is greatest in the late memory processes, which is the reverse of the pattern seen for the hippocampus. There are at least two possible explanations for this time-dependent change in the mPFC's importance in mnemonic processes. One is that the role of the mPFC gradually changes from a modulator of successful memory formation to a critical component of permanent memory storage. The other is that the mPFC plays the same role in several stages of memory, but its importance changes depending on the time-limited contribution of the hippocampus. Future studies that record neural activity from the mPFC during trace eyeblink conditioning will provide further detail concerning the mPFC's function in this learning.

In conclusion, the present study suggests that the mPFC is involved in acquisition of CRs as well as in the early stage of memory consolidation in trace eyeblink conditioning, and that this process is NMDA receptor dependent. Given that the brain circuitry that is involved in trace eyeblink conditioning covers 
multiple regions of the brain, it will be interesting to investigate acquisition and consolidation processes in other important brain components such as the hippocampus and the cerebellum, which may be closely correlated with processes in the mPFC. Such investigations may provide additional insight into the process of memory formation from the viewpoint of cooperative interaction among multiple regions of the brain.

\section{Materials and Methods}

\section{Subjects}

The subjects were male Wistar rats (Japan SLC), weighing 220 $300 \mathrm{~g}$ ( $9 \mathrm{wk}$ old). The animals were housed in standard plastic cages in a colony room with a 12-h light/12-h dark cycle and were provided with water and food ad libitum. All experiments were performed in accordance with the guidelines established by the Institutional Animal Investigation Committee at the University of Tokyo and the United States National Institutes of Health "Guide for the Care and Use of Laboratory Animals." All efforts were made to optimize comfort and to minimize the use of animals.

\section{Implantation of guide cannulae for intracerebral infusion}

Rats were anesthetized with ketamine $(87 \mathrm{mg} / \mathrm{kg}$, i.p., Sankyo) and xylazine (13 mg/kg, i.p., Bayer) and their heads were placed in stereotaxic frames (Narishige) with the skull surface in the horizontal plane. After the skull was exposed by incision along the midline, small holes (1.6-mm diameter) were drilled on each side of the skull at the following coordinates (in millimeters from bregma): [anteroposterior $(\mathrm{AP})+4.0$, mediolateral $(\mathrm{ML})+0.7]$ and [AP +1.2, ML -0.7$]$. Two single-guide cannulae (26 gauge, Plastic One) were implanted at an angle of $\pm 20^{\circ}$ through each hole, and their tips were directed to the following coordinates: $[\mathrm{AP}+3.0$, $\mathrm{ML}+0.7$, dorsoventral (DV) -2.8 to the skull surface] and [AP $+2.2, \mathrm{ML}-0.7, \mathrm{DV}-2.8$ ]. Since the tip of the infusion cannula protruded into the prelimbic area $1 \mathrm{~mm}$ from the guide cannula, the final infusion positions were at the following coordinates: $[\mathrm{AP}+2.6, \mathrm{ML} \pm 0.7, \mathrm{DV}-3.7]$. The guide cannulae were fixed on the skull with dental cement and small stainless steel screws. Stainless steel stylets, which extended $1 \mathrm{~mm}$ beyond the tip of the guide cannulae, were placed inside the guide cannulae to prevent occlusion. Four Teflon-coated stainless steel wires (No. 7910; A-M systems) were soldered to connector pins, which were implanted subcutaneously in the left upper eyelid. Then these connector pins were fixed on the skull with dental cement and stainless steel screws. The animals were injected with gentamycin sulfate $(8 \mathrm{mg} / \mathrm{kg}$, i.p., Schering-Plough) and warmed until they moved spontaneously.

\section{Intracerebral microinfusion and drugs}

Rats were mildly restrained in cotton sacks. The stylet was replaced by an infusion cannula (33 gauge), which was connected to a $1-\mu \mathrm{L}$ Hamilton microsyringe mounted on a microinfusion pump (Univentor). The tip of the infusion cannula protruded into the prelimbic area $1 \mathrm{~mm}$ from the guide cannula. The rats were bilaterally infused (always at a speed of $0.5 \mu \mathrm{L} / \mathrm{min}$ ) with either muscimol $\mathrm{HBr}(0.5 \mu \mathrm{g}$, Sigma-RBI) or D,L-2-amino-5phosphonovaleric acid (APV) (5 $\mu$ g, Sigma-RBI) in $0.5 \mu \mathrm{L} \mathrm{PBS,} \mathrm{or}$ they were infused only with $0.5 \mu \mathrm{L}$ PBS. These doses were chosen based on recent studies of the rat neocortex (Mello et al. 2000; Ferreira et al. 2002). After infusion, the infusion cannula was left in the brain for $1 \mathrm{~min}$ to allow the drug to diffuse from the cannula tip and then it was replaced by the stylet. Rats received the microinfusion $10 \mathrm{~min}$ before (the pre-conditioning group), immediately after (the post-conditioning group), or $3 \mathrm{~h}$ after (the 3 -h group) their daily conditioning. Several studies using similar intracortical infusion procedures have reported that the drugs' diffusion was restricted to within a $1-\mathrm{mm}$ radius, and that the time required to diffuse away from the infusion sites was between
1 and $2 \mathrm{~h}$ for muscimol and between $30 \mathrm{~min}$ and $1 \mathrm{~h}$ for APV (Martin 1991; Izquierdo et al. 1997; Steele and Morris 1999). However, the exact drug diffusion into each animal was unknown, because we did not measure the spread of the drug directly.

\section{Conditioning apparatus}

Four cylindrical Plexiglas containers $(15 \mathrm{~cm}$ in diameter and 25 $\mathrm{cm}$ high) were placed in a sound- and light-attenuating chamber. One rat was placed in each container. A lightweight cable was connected to the connector pins secured on the animal's head. The CS was a $350-\mathrm{msec}$ tone $(5 \mathrm{kHz}, 85 \mathrm{~dB})$ with a $5-\mathrm{msec}$ rise and a 5 -msec fall time, which was delivered from a speaker $(16.5 \mathrm{~cm}$ in diameter) placed above the containers. The US was a 100-msec periorbital shock (100 Hz square pulses) delivered through a pair of electrodes implanted in the left upper eyelid; its intensity was carefully calibrated to give the minimal current required to elicit an eyeblink/head-turn response, and adjusted daily for each rat $(0.5-5.0 \mathrm{~mA})$. The current intensity presented during the conditioning was not different between the groups (data not shown). A stimulus-free trace interval of $500 \mathrm{msec}$ was interposed between the end of the CS and the US onset in the trace paradigm. In the delay paradigm, the US terminated simultaneously with the CS (the interstimulus interval was $250 \mathrm{msec}$ ). In the pseudoconditioning paradigm, the US was presented with a random interval between 1 and $19 \mathrm{sec}$ after the CS onset. The CR was monitored through electromyographic (EMG) activity, recorded with another pair of implanted electrodes.

\section{Behavioral procedure}

No less than $5 \mathrm{~d}$ after the surgery, spontaneous eyeblinks were recorded for two session days in the same way as during the conditioning session, except that no stimuli were presented. A daily session consisted of 100 trials grouped into 10 blocks, each of which included nine CS-US paired trials followed by one CSalone trial. Trials were separated by a variable intertrial interval pseudorandomized between 20 and $40 \mathrm{sec}$, with a mean of $30 \mathrm{sec}$. All experiments were performed during the light phase of the light/dark cycle.

\section{Histology}

At the end of the experiment, each animal was intraperitoneally injected with an excess amount of sodium pentobarbital (>80 $\mathrm{mg} / \mathrm{kg}$, Dainippon Pharmaceutical Co.) and perfused intracardially with $0.9 \%$ saline, followed by phosphate-buffered $10 \%$ formalin. The brain was removed from the skull and stored in 10\% formalin for a few days. After infiltration with $30 \%$ sucrose, it was frozen, sectioned at $60-\mu \mathrm{m}$ thickness, and stained with cresyl violet. The sections were subsequently examined under a light microscope and the locations of the cannula tips were drawn onto plates from the stereotaxic atlas of the rat brain (Paxinos and Watson 1986). The distance between the targeted location and the actual location of the cannula tips was estimated by calculating the distance from the AP and DV coordinates.

\section{EMG analysis}

The EMG activity was band-pass filtered between 0.15 and 1.0 $\mathrm{kHz}$ and fed into a computer with a sampling rate of $10 \mathrm{kHz}$. The maximum amplitude of the EMG signals during a time period of $t \pm 1 \mathrm{msec}$ was calculated and designated the EMG amplitude at $t$. The mean + SD of the EMG amplitudes during the pre-CS period (0-300 msec before CS onset) of 100 trials was defined as the threshold. After extracting the threshold from the raw EMG amplitude data, we calculated four values from this EMG amplitude data in each trial as follows: (1) a "Pre" value that was calculated by averaging the EMG amplitude data for $300 \mathrm{msec}$ before the CS onset; (2) a "Startle" value that was calculated by averaging the EMG amplitude data for 30 msec after the CS onset; (3) a "CR" value that was calculated by averaging all of the EMG amplitude data for all sets of the 100-msec periods of EMG data between 50 msec after the CS onset and the US onset; and (4) an "Adaptive

\section{Learning \& Memory}


CR" value that was calculated by averaging the EMG amplitude data for the period 0-200 msec before the US onset in the CS-US paired trials. The time window was extended by a subsequent 100 msec for the CR value and the Adaptive CR value calculations in the CS-alone trials. If the Pre value exceeded $10 \%$ of the threshold, the trial was regarded as a hyperactivity trial and excluded from any further analysis. A trial was assumed to contain a CR or an adaptive $C R$ if the $C R$ value or the Adaptive $C R$ value exceeded $10 \%$ of the threshold, respectively. The ratio of the number of trials containing the CR or the adaptive CR to the total number of trials (excluding the hyperactivity trials) was calculated and denoted the $\mathrm{CR} \%$ or the adaptive CR\%, respectively. The frequencies of the CRs (CR\%) and the adaptive CRs (adaptive CR\%) were expressed as a percentage for each session.

To show the temporal pattern of the CR, the trace of the average EMG amplitude was made as follows: The EMG amplitude data for each rat were averaged over the total number of trials (excluding the hyperactivity trials) for each day. These trialaveraged EMG amplitude data were normalized to the timeaveraged values for $300 \mathrm{msec}$ before the CS onset. Since the data were calculated from the total trials (excluding the hyperactivity trials), the temporal pattern of the normalized EMG amplitude data did not depend on the criterion used for detecting the CR. Furthermore, the latencies of the CR peak and CR onset were measured for a quantitative analysis of the temporal pattern of the CR. The CR peak latency was defined as the time interval from the CS onset to the peak of the EMG amplitude, and the CR onset latency was defined as the time interval from the CS onset to the time when the averaged EMG amplitude first met the criterion for a CR. These values were averaged over those trials in each session that were judged to contain a CR.

\section{Statistical analysis}

All data were expressed as the mean \pm SEM. Statistical significance was determined by a two-way ANOVA with repeated measures, by a one-way ANOVA, or by a $t$-test using SPSS statistical software.

\section{Acknowledgments}

We thank B.L. McNaughton for comments on the manuscript. This work was supported by grants from the Ministry of Education, Culture, Sports, Science, and Technology of Japan (\#16390015) and the Core Research for Evolution Science and Technology of the Japan Science and Technology Agency. K.T. is the recipient of a Fellowship for Young Scientists from the Japan Society for the Promotion of Science.

\section{References}

Attwell, P.J., Cooke, S.F., and Yeo, C.H. 2002. Cerebellar function in consolidation of a motor memory. Neuron 34: 1011-1020.

Beylin, A.V., Gandhi, C.C., Wood, G.E., Talk, A.C., Matzel, L.D., and Shors, T.J. 2001. The role of the hippocampus in trace conditioning: Temporal discontinuity or task difficulty? Neurobiol. Learn. Mem. 76: 447-461.

Compte, A., Brunel, N., Goldman-Rakic, P.S., and Wang, X.J. 2000. Synaptic mechanisms and network dynamics underlying spatial working memory in a cortical network model. Cereb. Cortex 10: $910-923$.

Cooke, S.F., Attwell, P.J., and Yeo, C.H. 2004. Temporal properties of cerebellar-dependent memory consolidation J. Neurosci. 24: 2934-2941.

Eichenbaum, H. 2002. The cognitive neuroscience of memory. Oxford University Press, New York.

Feenstra, M.G., Botterblom, M.H., and van Uum, J.F. 2002. Behavioral arousal and increased dopamine efflux after blockade of NMDA-receptors in the prefrontal cortex are dependent on activation of glutamatergic neurotransmission. Neuropharmacology 42: $752-763$.

Ferreira, G., Gutierrez, R., De La Cruz, V., and Bermudez-Rattoni, F. 2002. Differential involvement of cortical muscarinic and NMDA receptors in short- and long-term taste aversion memory. Eur. J. Neurosci. 16: 1139-1145.

Fuster, J.M. 1997. The prefrontal cortex-Anatomy, physiology, and neuropsychology of the frontal lobe, 3rd ed. Lippincott-Raven,
Philadelphia, PA.

. 2001. The prefrontal cortex-An update: Time is of the essence. Neuron 30: 319-333.

Goldman-Rakic, P.S. 1990. Cellular and circuit basis of working memory in prefrontal cortex of nonhuman primates. Prog. Brain Res. 85: $325-335$.

Green, J.T. and Woodruff-Pak, D.S. 2000. Eyeblink classical conditioning: Hippocampal formation is for neutral stimulus associations as cerebellum is for association-response. Psychol. Bull. 126: $138-158$.

Hernandez, L.L. and Powell, D.A. 1983. Naloxone induces multiple effects on aversive Pavlovian conditioning in rabbits. Behav. Neurosci. 97: 478-491.

Hirsch, J.C. and Crepel, F. 1991. Blockade of NMDA receptors unmasks long-term depression in synaptic efficacy in rat prefrontal neurons in vitro. Exp. Brain Res. 85: 621-624.

Izquierdo, I., Quillfeldt, J.A., Zanatta, M.S., Quevedo, J., Schaeffer, E., Schmitz, P.K., and Medina, J.H. 1997. Sequential role of hippocampus and amygdala, entorhinal cortex and parietal cortex in formation and retrieval of memory for inhibitory avoidance in rats. Eur. J. Neurosci. 9: 786-793.

Jay, T.M., Burette, F., and Laroche, S. 1995. NMDA receptor-dependent long-term potentiation in the hippocampal afferent fibre system to the prefrontal cortex in the rat. Eur. J. Neurosci. 7: 247-250.

Kim, J.J., Clark, R.E., and Thompson, R.F. 1995. Hippocampectomy impairs the memory of recently, but not remotely, acquired trace eyeblink conditioned responses. Behav. Neurosci. 109: 195-203.

Kishimoto, Y., Kawahara, S., Mori, H., Mishina, M., and Kirino, Y. 2001. Long-trace interval eyeblink conditioning is impaired in mutant mice lacking the NMDA receptor subunit $\epsilon 1$. Eur. J. Neurosci. 13: $1221-1227$.

Kolb, B. 1984. Functions of the frontal cortex of the rat: A comparative review Brain Res. Rev. 8: 65-98.

Kronforst-Collins, M.A. and Disterhoft, J.F. 1998. Lesions of the caudal area of rabbit medial prefrontal cortex impair trace eyeblink conditioning. Neurobiol. Learn. Mem. 69: 147-162.

Martin, J.H. 1991. Autoradiographic estimation of the extent of reversible inactivation produced by microinjection of lidocaine and muscimol in the rat. Neurosci. Lett. 127: 160-164.

McGlinchey-Berroth, R., Carrillo, M.C., Gabrieli, J.D., Brawn, C.M., and Disterhoft, J.F. 1997. Impaired trace eyeblink conditioning in bilateral, medial-temporal lobe amnesia. Behav. Neurosci. 111: $873-882$

McLaughlin, J., Skaggs, H., Churchwell, J., and Powell, D.A. 2002. Medial prefrontal cortex and Pavlovian conditioning: Trace versus delay conditioning Behav. Neurosci. 116: 37-47.

Mello, E., Souza, T., Vianna, M.R.M., Rodrigues, C., Quevedo, J., Moleta, B.A., and Izquierdo, I. 2000. Involvement of the medial precentral prefrontal cortex in memory consolidation for inhibitory avoidance learning in rats. Pharmacol. Biochem. Behav. 66: 615-622.

Moyer, J.R., Deyo, R.A., and Disterhoft, J.F. 1990. Hippocampectomy disrupts trace eye-blink conditioning in rabbits. Behav. Neurosci. 104: $243-252$.

Paxinos, G. and Watson, C. 1986. The rat brain in stereotaxic coordinates. Academic Press, San Diego, CA.

Powell, D.A. and Churchwell, J. 2002. Mediodorsal thalamic lesions impair trace eyeblink conditioning in the rabbit. Learn. Mem. 9: 10-17.

Powell, D.A., Skaggs, H., Churchwell, J., and McLaughlin, J. 2001. Posttraining lesions of the medial prefrontal cortex impair performance of Pavlovian eyeblink conditioning but have no effect on concomitant heart rate changes in rabbits (Oryctolagus cuniculus). Behav. Neurosci. 115: 1029-1038.

Ryou, J.W., Cho, S.Y., and Kim, H.T. 2001. Lesions of the entorhinal cortex impair acquisition of hippocampal-dependent trace conditioning. Neurobiol. Learn. Mem. 75: 121-127.

Scavio, M.J., Clift, P.S., and Wills, J.C. 1992. Posttraining effects of amphetamine, chlorpromazine, ketamine, and scopolamine on the acquisition and extinction of the rabbit's conditioned nictitating membrane response. Behav. Neurosci. 106: 900-908.

Solomon, P.R., Vander Schaaf, E.R., Thompson, R.F., and Weisz, D.J. 1986. Hippocampus and trace conditioning of the rabbit's classically conditioned nictitating membrane response. Behav. Neurosci. 100: $729-744$

Steele, R.J. and Morris, R.G.M. 1999. Delay-dependent impairment of a matching-to-place task with chronic and intrahippocampal infusion of the NMDA-antagonist D-AP5. Hippocampus 9: 118-136.

Takatsuki, K., Kawahara, S., Takehara, K., Kishimoto, Y., and Kirino, Y. 2001. Effects of the noncompetitive NMDA receptor antagonist MK-801 on classical eyeblink conditioning in mice. Neuropharmacology 41: 618-628.

Takehara, K., Kawahara, S., Takatsuki, K., and Kirino, Y. 2002. 


\section{Takehara-Nishiuchi et al.}

Time-limited role of the hippocampus in the memory for trace eyeblink conditioning in mice. Brain Res. 951: 183-190.

Takehara, K., Kawahara, S., and Kirino, Y. 2003a. Time-dependent reorganization of the brain components underlying memory retention in trace eyeblink conditioning. J. Neurosci. 23: 9897-9905. . 2003b. NMDA receptors in the medial prefrontal cortex are crucial for memory formation during trace eyeblink conditioning. Abstract Viewer Itinerary Planner, Program No. 87.11. Society for Neuroscience, Washington, D.C.

Takehara, K., Kawahara, S., Munemoto, Y., Kuriyama, H., Mori, H. Mishina, M., and Kirino, Y. 2004. The N-Methyl-D-aspartate (NMDA)-type glutamate receptor GluRe2 is important for delay and trace eyeblink conditioning in mice. Neurosci. Lett. 364: 43-47.

Thompson, L.T. and Disterhoft, J.F. 1997. N-methyl-D-aspartate receptors in associative eyeblink conditioning: Both MK-801 and phencyclidine produce task- and dose-dependent impairments. $J$. Pharmacol. Exp. Ther. 281: 928-940.

Thompson, R.F., Bao, S., Chen, L., Cipriano, B.D., Grethe, J.S., Kim, J.J., Thompson, J.K., Tracy, J.A., Weninger, M.S., and Krupa, D.J. 1997. Associative learning. Int. Rev. Neurobiol. 41: 151-189.
Weible, A.P., McEchron, M.D., and Disterhoft, J.F. 2000. Cortical involvement in acquisition and extinction of trace eyeblink conditioning. Behav. Neurosci. 114: 1058-1067.

Weible, A.P., Weiss, C., and Disterhoft, J.F. 2003. Activity profiles of single neurons in caudal anterior cingulate cortex during trace eyeblink conditioning in the rabbit. J. Neurophysiol. 90: 599-612.

Weiss, C. and Disterhoft, J.F. 1996. Eyeblink conditioning, motor control, and the analysis of limbic-cerebellar interactions. Behav. Brain Sci. 19: 479-481.

Woodruff-Pak, D.S., Lavond, D.G., and Thompson, R.F. 1985. Trace conditioning: Abolished by cerebellar nuclear lesions but not lateral cerebellar cortex aspirations. Brain Res. 348: 249-260.

Yang, C.R. and Seamans, J.K. 1996. Dopamine D1 receptor actions in layers V-VI rat prefrontal cortex neurons in vitro: Modulation of dendritic-somatic signal integration. J. Neurosci. 16: 1922-1935.

Received June 4, 2005; accepted in revised form September 28, 2005.

\section{Learning \& Memory}




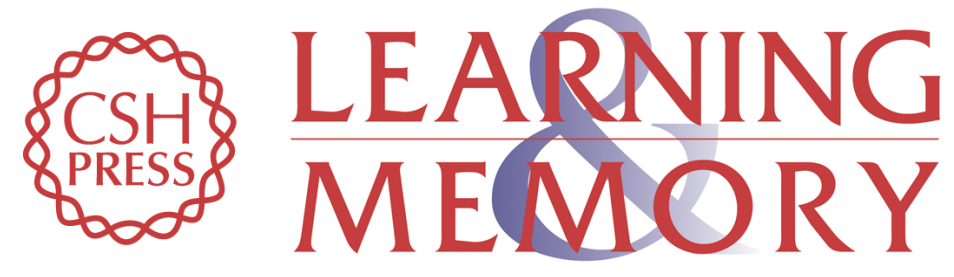

\section{NMDA receptor-dependent processes in the medial prefrontal cortex are important for acquisition and the early stage of consolidation during trace, but not delay eyeblink conditioning}

Kaori Takehara-Nishiuchi, Shigenori Kawahara and Yutaka Kirino

Learn. Mem. 2005, 12:

Access the most recent version at doi:10.1101//m.5905

References This article cites 38 articles, 5 of which can be accessed free at: http://learnmem.cshlp.org/content/12/6/606.full.html\#ref-list-1

License

Email Alerting

Receive free email alerts when new articles cite this article - sign up in the box at the Service top right corner of the article or click here. 